Data Article

\title{
Data of innovation ambidexterity as a mediator in the absorptive capacity effect on sustainable competitive advantage
}

\author{
Astadi Pangarso a, b, *, Endang Siti Astuti a , Kusdi Raharjo a, \\ Tri Wulida Afrianty ${ }^{a}$ \\ a Business Administration Department, Administrative Science Faculty, Brawijaya University, Indonesia \\ ${ }^{\mathrm{b}}$ Business Administration Department, Telkom University, Indonesia
}

\section{A R T I C L E I N F O}

\section{Article history:}

Received 18 November 2019

Received in revised form 20 January 2020

Accepted 20 January 2020

Available online 29 January 2020

\section{Keywords:}

Innovation ambidexterity

Absorptive capacity

Sustainable competitive advantage

Indonesian higher education

\begin{abstract}
A B S T R A C T
This data article shows the nexus between absorptive capacity (X), innovation ambidexterity (Y1) and sustainable competitive advantage (Y2). There are three nexus points between the constructs, namely the direct nexuses of $\mathrm{X}$ to $\mathrm{Y} 1, \mathrm{X}$ to $\mathrm{Y} 2$ and the indirect nexus from $X$ to $Y 2$ through $Y 1$. The raw data of 530 selfadministrated questionnaires were obtained from 64 nonvocational private higher education institutions in the Bandung area of West Java, Indonesia. Data analyzing were conducted using SPPS and Smart PLS. The data are useful as the data can be reproduced, reused and reanalysed. This data article also opens up better research opportunities going forward through collaboration with other researchers.
\end{abstract}

๑) 2020 The Author(s). Published by Elsevier Inc. This is an open access article under the CC BY license (http://creativecommons. org/licenses/by/4.0/).

\footnotetext{
* Corresponding author. Business Administration Department, Administrative Science Faculty, Brawijaya University, Indonesia.

E-mail addresses: astadipangarso@student.ub.ac.id, astadipangarso@telkomuniversity.ac.id (A. Pangarso).
} 
Specifications Table

\begin{tabular}{|c|c|}
\hline Subject & Business and International Management \\
\hline Specific subject area & Absorptive Capacity, Innovation Ambidexterity, Sustainable Competitive Advantage \\
\hline \multirow[t]{2}{*}{ Type of data } & Table \\
\hline & Figure \\
\hline How data were acquired & $\begin{array}{l}\text { The data were collected using a survey with questionnaires. The data were analyzed using } \\
\text { SPSS and Smart PLS. The link of the questionnaire: https://data.mendeley.com/datasets/ } \\
\text { z2y8gmxtrb/3\#file-e6fb3164-e259-47d1-b4fc-0d0d2c41b2fd }\end{array}$ \\
\hline Data format & $\begin{array}{l}\text { Raw } \\
\text { Smart PLS data }\end{array}$ \\
\hline $\begin{array}{l}\text { Parameters for data } \\
\text { collection }\end{array}$ & $\begin{array}{l}\text { The sample consisted of } 530 \text { respondents. The data were collected using a self- } \\
\text { administrated questionnaire from } 64 \text { non-vocational private higher education institutions. }\end{array}$ \\
\hline $\begin{array}{l}\text { Description of data } \\
\text { collection }\end{array}$ & $\begin{array}{l}\text { The questionnaire data were collected through a survey. The collection of questionnaires for } \\
\text { each non-vocational private higher education institutions was done through } 1 \text { key person/ } \\
\text { enumerator. The researcher submits the research permission application letter to the non- } \\
\text { vocational private higher education institutions with the help of the enumerators. After } \\
\text { being allowed to distribute the questionnaire, the researcher discusses with the } \\
\text { enumerators how the technical implementation of the questionnaire is distributed. } \\
\text { Researcher offer two types of questionnaires to enumerators. The questionnaire can be } \\
\text { distributed offline and online following the policies of each non-vocational private higher } \\
\text { education institutions. The researcher entrusted the questionnaire in the form of a hardcopy } \\
\text { or a link of a google form to the enumerators to be distributed to respondents. The } \\
\text { researcher communicate with the enumerators by the WhatsApp number or cellular phone } \\
\text { so the process of collecting questionnaire data could be monitored and quick collected from } \\
\text { each non-vocational private higher education institutions. }\end{array}$ \\
\hline \multirow[t]{3}{*}{ Data source location } & Institution: Non-vocational private higher education institution \\
\hline & City/Town/Region: Bandung area, West Java \\
\hline & Country: Indonesia \\
\hline \multirow[t]{3}{*}{ Data accessibility } & Repository name: Mendeley Data \\
\hline & Data identification number: 10.17632/z2y8gmxtrb.3 \\
\hline & Direct URL to data: https://data.mendeley.com/datasets/z2y8gmxtrb/3 \\
\hline
\end{tabular}

\footnotetext{
Value of the Data

- This data article has the potential for the research community to replicate it using different quantitative data software processing. This is in order to be able to compare the results between the software (for example: AMOS, LISREL, Warp PLS, PLS using R, Adenco etc).

- This data article is expected to open up opportunities for collaboration with other researchers related to future research with the following constructs: absorptive capacity, innovation ambidexterity and sustainable competitive advantage.

- The Indonesian leaders of the non-vocational private higher education institutions, the LLDIKTI (Indonesian higher education administrator institution) and also the researchers, will get benefits from this data related to increasing the non-vocational private higher education institutions sustainable competitive advantage.

- This data article is useful because it will become the basis for the interpretation of the next research article publication related to the mediation role of innovation ambidexterity on the effect and prediction of absorptive capacity to sustainable competitive advantage.
}

\section{Data description}

The questionnaire data consisted of 3 research variables, namely absorptive capacity (AC) as the independent variable (X), innovation ambidexterity (IA) as the first dependent variable (Y1) and sustainable competitive advantage (SCA) as the second dependent variable (Y2). The questionnaire consists of 60 statement indicators that must be answered based on the Likert scale of 1-5 (very disagree to very agree). Variable X consists of 19 indicator items adopted from Ref. [1]; variable Y1 consists of 9 indicator items adopted from Refs. [2,3]; and variable Y2 consists of 32 indicator items adopted from Refs. [4,5]. Questionnaire data were obtained from Research Data [6].

This questionnaire belongs to the category of self-administration and therefore it needs to be tested for common method variance [7]. Self-administrated questionnaires can potentially lead to a common method bias. Therefore this questionnaire needs to be checked in order to whether this research is free 
from common method bias. The evaluation of common method variance (CMV) using the Harman single factor test has been carried out and the variance value is $38.837 \%$. If the percentage variance is below $50 \%$, then it can be said that the measurement of the research indicators has passed the common method bias. Table 1 states the results of the Harman single factor test for CMV testing using SPSS.

From the results of the descriptive statistics as can be seen in Table 2, the demographics of the respondents in this research were balanced between men and women. The highest number of educated level was a Master's. Furthermore, the research respondents were dominated by full-time lecturers.

The questionnaire data analyzing were done using the smart PLS protocol according to Ref. [8]. Data analyzing using smart PLS consists of the measurement model evaluation and structural model evaluation. The measurement model calculation can be seen sequentially in Tables 3-5. Smart PLS preparation begins from assessing the measurement model through indicator reliability, internal

Table 1

Harman single factor test Total Variance Explained.

\begin{tabular}{|c|c|c|c|c|c|c|}
\hline \multirow[t]{2}{*}{ Component } & \multicolumn{3}{|c|}{ Initial Eigenvalues } & \multicolumn{3}{|c|}{ Extraction Sums of Squared Loadings } \\
\hline & Total & $\%$ of Variance & Cumulative \% & Total & $\%$ of Variance & Cumulative \% \\
\hline 1 & 23.302 & 38.837 & 38.837 & 23.302 & 38.837 & 38.837 \\
\hline 2 & 3.004 & 5.007 & 43.844 & & & \\
\hline 3 & 2.635 & 4.392 & 48.237 & & & \\
\hline 4 & 1.991 & 3.318 & 51.555 & & & \\
\hline 5 & 1.564 & 2.607 & 54.161 & & & \\
\hline 6 & 1.471 & 2.452 & 56.614 & & & \\
\hline 7 & 1.446 & 2.409 & 59.023 & & & \\
\hline 8 & 1.204 & 2.007 & 61.030 & & & \\
\hline 9 & 1.165 & 1.942 & 62.972 & & & \\
\hline 10 & 1.060 & 1.766 & 64.738 & & & \\
\hline 11 & .987 & 1.645 & 66.383 & & & \\
\hline 12 & .869 & 1.448 & 67.830 & & & \\
\hline 13 & .821 & 1.369 & 69.199 & & & \\
\hline 14 & .781 & 1.302 & 70.501 & & & \\
\hline 15 & .744 & 1.240 & 71.741 & & & \\
\hline 16 & .724 & 1.207 & 72.948 & & & \\
\hline 17 & .686 & 1.144 & 74.092 & & & \\
\hline 18 & .677 & 1.128 & 75.220 & & & \\
\hline 19 & .655 & 1.092 & 76.312 & & & \\
\hline 20 & .617 & 1.028 & 77.340 & & & \\
\hline 21 & .608 & 1.013 & 78.352 & & & \\
\hline 22 & .589 & .982 & 79.334 & & & \\
\hline 23 & .570 & .951 & 80.285 & & & \\
\hline 24 & .551 & .918 & 81.203 & & & \\
\hline 25 & .545 & .908 & 82.111 & & & \\
\hline 26 & .494 & .823 & 82.934 & & & \\
\hline 27 & .475 & .791 & 83.725 & & & \\
\hline 28 & .465 & .776 & 84.501 & & & \\
\hline 29 & .458 & .764 & 85.265 & & & \\
\hline 30 & .451 & .752 & 86.016 & & & \\
\hline 31 & .437 & .728 & 86.745 & & & \\
\hline 32 & .430 & .716 & 87.461 & & & \\
\hline 33 & .400 & .666 & 88.127 & & & \\
\hline 34 & .396 & .660 & 88.787 & & & \\
\hline 35 & .383 & .638 & 89.425 & & & \\
\hline 36 & .361 & .602 & 90.026 & & & \\
\hline 37 & .351 & .584 & 90.611 & & & \\
\hline 38 & .341 & .568 & 91.178 & & & \\
\hline 39 & .332 & .553 & 91.731 & & & \\
\hline 40 & .328 & .547 & 92.278 & & & \\
\hline 41 & .315 & .524 & 92.802 & & & \\
\hline
\end{tabular}


Table 1 (continued)

\begin{tabular}{|c|c|c|c|c|c|c|}
\hline \multirow[t]{2}{*}{ Component } & \multicolumn{3}{|c|}{ Initial Eigenvalues } & \multicolumn{3}{|c|}{ Extraction Sums of Squared Loadings } \\
\hline & Total & $\%$ of Variance & Cumulative \% & Total & $\%$ of Variance & Cumulative \% \\
\hline 42 & .309 & .515 & 93.318 & & & \\
\hline 43 & .306 & .510 & 93.828 & & & \\
\hline 44 & .292 & .487 & 94.315 & & & \\
\hline 45 & .292 & .487 & 94.802 & & & \\
\hline 46 & .287 & .478 & 95.280 & & & \\
\hline 47 & .264 & .440 & 95.720 & & & \\
\hline 48 & .253 & .422 & 96.142 & & & \\
\hline 49 & .243 & .405 & 96.547 & & & \\
\hline 50 & .240 & .400 & 96.947 & & & \\
\hline 51 & .227 & .379 & 97.325 & & & \\
\hline 52 & .213 & .355 & 97.681 & & & \\
\hline 53 & .210 & .350 & 98.031 & & & \\
\hline 54 & .197 & .328 & 98.360 & & & \\
\hline 55 & .189 & .315 & 98.674 & & & \\
\hline 56 & .182 & .303 & 98.977 & & & \\
\hline 57 & .173 & .288 & 99.265 & & & \\
\hline 58 & .159 & .264 & 99.529 & & & \\
\hline 59 & .154 & .257 & 99.787 & & & \\
\hline 60 & .128 & .213 & 100.000 & & & \\
\hline
\end{tabular}

Extraction Method: Principal Component Analysis.

consistency reliability, convergent validity and discriminant validity [8]. The reliability of the indicator is known by the loading factor value $(>0.708)$, which means that the indicator is reliable. The factor loading in Table 3 for each indicator must be more than 0.708 . If the factor loading value is less than 0.708 , then it will be removed and not included in the next evaluation process. Only the indicators with loading factor values of 0.708 or more are included in the next evaluation process. From Fig. 1, it can be seen that there are indicators whose values are the same or more than 0.708 .

Internal consistency reliability is measured based on composite reliability values $(C R)>0.70$, which means that the research variable is reliable. The convergent validity is represented by the value of Average Variance Extracted/AVE ( $>0.50$ ), which means that the variable can explain more than $50 \%$ of the variance of the indicators. The AVE value in Table 4 for each variable must be higher than 0.50 .

Furthermore, the discriminant validity uses HeteroTraitMonoTrait (HTMT) values. The HTMT or discriminant validity values in Table 5 for each research variable must be less than 0.90 . The HTMT values of the research variables were below 0.90 [9], which means that the research variables have good discriminant validity.

All of the indicators and variables have passed the measurement model evaluation process and have fulfilled all of the rules of thumb, as can be seen in Fig. 1.

Table 2

Respondent profile.

\begin{tabular}{llll}
\hline Characteristics & Sub characteristics & Frequency & Percentage (\%) \\
\hline Gender & Male & 277 & 52 \\
& Female & 253 & 48 \\
Education level & Bachelor & 35 & 7 \\
& Master & 380 & 72 \\
Structural position & Ph.D/DR. & 115 & 21 \\
& No & 134 & 25 \\
Structural Position Name & Yes & 396 & 75 \\
& Lecturer & 277 & 52 \\
& Quality Assurance & 52 & 10 \\
\hline
\end{tabular}


Table 3

Loading factors.

\begin{tabular}{|c|c|c|c|}
\hline & Absorptive Capacity & Innovation Ambidexterity & Sustainable Competitive Advantage \\
\hline $\mathrm{X} 10$ & 0.754 & & \\
\hline $\mathrm{X} 11$ & 0.690 & & \\
\hline $\mathrm{X} 12$ & 0.718 & & \\
\hline $\mathrm{X} 13$ & 0.724 & & \\
\hline $\mathrm{X} 14$ & 0.723 & & \\
\hline X15 & 0.775 & & \\
\hline $\mathrm{X} 16$ & 0.804 & & \\
\hline $\mathrm{X} 17$ & 0.765 & & \\
\hline $\mathrm{X} 18$ & 0.677 & & \\
\hline $\mathrm{X} 19$ & 0.710 & & \\
\hline $\mathrm{X} 2$ & 0.696 & & \\
\hline $\mathrm{X} 3$ & 0.753 & & \\
\hline $\mathrm{X} 4$ & 0.799 & & \\
\hline $\mathrm{X} 5$ & 0.780 & & \\
\hline $\mathrm{X} 6$ & 0.773 & & \\
\hline $\mathrm{X} 7$ & 0.706 & & \\
\hline $\mathrm{X} 8$ & 0.610 & & \\
\hline X9 & 0.603 & & \\
\hline Y1.1 & & 0.755 & \\
\hline $\mathrm{Y} 1.2$ & & 0.714 & \\
\hline Y1.3 & & 0.645 & \\
\hline Y1.4 & & 0.722 & \\
\hline Y1.5 & & 0.801 & \\
\hline Y1.6 & & 0.781 & \\
\hline Y1.7 & & 0.713 & \\
\hline Y1.8 & & 0.825 & \\
\hline Y1.9 & & 0.816 & \\
\hline Y2.1 & & & 0.525 \\
\hline Y2.10 & & & 0.560 \\
\hline Y2.11 & & & 0.634 \\
\hline Y2.12 & & & 0.529 \\
\hline Y2.13 & & & 0.553 \\
\hline Y2.14 & & & 0.582 \\
\hline Y2.15 & & & 0.551 \\
\hline Y2.16 & & & 0.531 \\
\hline Y2.17 & & & 0.705 \\
\hline Y2.18 & & & 0.767 \\
\hline Y2.19 & & & 0.484 \\
\hline Y2.2 & & & 0.474 \\
\hline Y2.20 & & & 0.761 \\
\hline Y2.21 & & & 0.759 \\
\hline Y2.22 & & & 0.683 \\
\hline Y2.23 & & & 0.669 \\
\hline Y2.24 & & & 0.760 \\
\hline Y2.25 & & & 0.798 \\
\hline Y2.26 & & & 0.777 \\
\hline Y2.27 & & & 0.612 \\
\hline Y2.28 & & & 0.733 \\
\hline Y2.29 & & & 0.665 \\
\hline Y2.3 & & & 0.619 \\
\hline Y2.30 & & & 0.012 \\
\hline Y2.31 & & & 0.055 \\
\hline Y2.32 & & & 0.046 \\
\hline Y2.4 & & & 0.589 \\
\hline Y2.5 & & & 0.695 \\
\hline Y2.6 & & & 0.676 \\
\hline Y2.7 & & & 0.406 \\
\hline Y2.8 & & & 0.661 \\
\hline Y2.9 & & & 0.704 \\
\hline $\mathrm{X} 1$ & 0.658 & & \\
\hline
\end{tabular}


Table 4

CR and AVE values.

\begin{tabular}{lll}
\hline & Composite Reliability (CR) & Average Variance Extracted (AVE) \\
\hline Absorptive Capacity & 0.945 & 0.588 \\
Innovation Ambidexterity & 0.920 & 0.657 \\
Sustainable Competitive Advantage & 0.936 & 0.620 \\
\hline
\end{tabular}

Table 5

HTMT values.

Absorptive Capacity Innovation Ambidexterity Sustainable Competitive Advantage

\begin{tabular}{lll} 
Absorptive Capacity & & \\
Innovation Ambidexterity & 0.897 & 0.789 \\
Sustainable Competitive Advantage & 0.831 & A \\
\hline
\end{tabular}

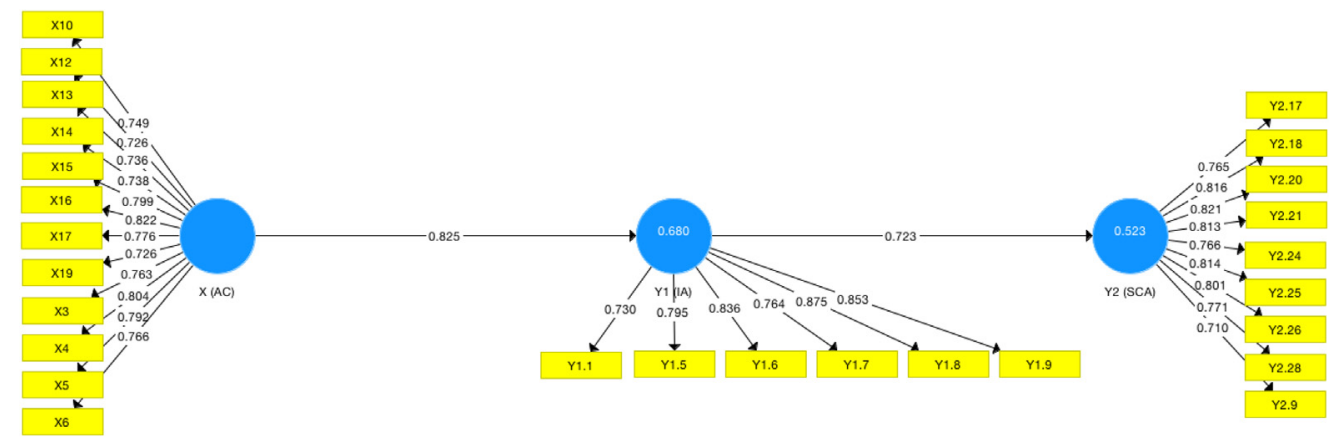

Fig. 1. Measurement model evaluation.

After evaluating the measurement model, it is followed by an evaluation of the structural model consisting the values of inner VIF, path coefficients, specific indirect effect, $R^{2}$ and $Q^{2}$ [8]. The Fig. 2 and Table 6 show the structural evaluation model in sequence from Table 6 through to 10. The inner VIF structural model for all of the research variables in Table 6 has fulfilled the cut-off in the range of 0.20 up to less than 5 , which means that all of the research variables are free from collinearity problems.

The number of hypotheses in the structural model consists of 2 direct nexus and one indirect nexus. The direct nexuses are $\mathrm{X}$ to $\mathrm{Y} 1$ and $\mathrm{Y} 1$ to $\mathrm{Y} 2$. The indirect nexus is $\mathrm{X}$ to $\mathrm{Y} 2$ through $\mathrm{Y} 1$. Table 7 shows that all of the direct nexus are significant.

In Table 7, the rule of thumb of the direct effect between the variables shows that the p-value is smaller than 0.05 and the t-statistics value is higher than 1.96 (using a $5 \%$ confidence level).

In Table 8, the rule of thumb for the specific indirect effect between the variables shows that the pvalue is less than 0.05 and the t-statistics value is higher than 1.96 (using a 5\% confidence level). Table 8 shows that the indirect nexus is significant.

Table 6

Inner VIF values.

\begin{tabular}{|c|c|c|c|}
\hline & Absorptive Capacity & Innovation Ambidexterity & Sustainable Competitive Advantage \\
\hline Absorptive Capacity & & 1.000 & \\
\hline Innovation Ambidexterity & & & 1.000 \\
\hline Sustainable Competitive Advantage & & & \\
\hline
\end{tabular}


Table 7

Path coefficients.

\begin{tabular}{|c|c|c|c|c|c|}
\hline & Original Sample (O) & $\begin{array}{l}\text { Sample Mean } \\
(\mathrm{M})\end{array}$ & $\begin{array}{l}\text { Standard Deviation } \\
\text { (STDEV) }\end{array}$ & $\begin{array}{l}\text { T Statistics } \\
(|\mathrm{O} / \mathrm{STDEV}|)\end{array}$ & P Values \\
\hline $\begin{array}{l}\text { Absorptive Capacity - > Innovation } \\
\text { Ambidexterity }\end{array}$ & 0.825 & 0.825 & 0.018 & 45.811 & 0.000 \\
\hline $\begin{array}{l}\text { Innovation Ambidexterity - > Sustainable } \\
\text { Competitive Advantage }\end{array}$ & 0.723 & 0.724 & 0.030 & 23.956 & 0.000 \\
\hline
\end{tabular}

The definition of significance of bold is if the p-value less than 0.05 .

Table 8

Specific indirect effect.

\begin{tabular}{|c|c|c|c|c|c|}
\hline & Original Sample (O) & Sample Mean (M) & $\begin{array}{l}\text { Standard Deviation } \\
\text { (STDEV) }\end{array}$ & $\begin{array}{l}\text { T Statistics } \\
(|\mathrm{O} / \mathrm{STDEV}|)\end{array}$ & P Values \\
\hline $\begin{array}{l}\text { Absorptive Capacity - > Innovation } \\
\text { Ambidexterity - > Sustainable } \\
\text { Competitive Advantage }\end{array}$ & 0.596 & 0.598 & 0.034 & 17.421 & 0.000 \\
\hline
\end{tabular}

The definition of significance of bold is if the p-value less than 0.05 .

In Table 9, the rule of thumb shows that the original sample (O) value of $R^{2}$ and the $p$-value are both smaller than 0.05 . The original sample $(0)$ values are higher than 0.25 . Furthermore, the $\mathrm{R}^{2}$ values between 0.5 and 0.75 indicate that the structural model has moderate explanatory power (see Table 9).

In Table 10, the rule of thumb shows that the values of $Q^{2}$ are higher than zero. All of the $Q^{2}$ values are in the range of $0.25-0.5$, which means that the structural model has medium predictive relevance.

All of the variables have passed the structural model evaluation process and they have fulfilled all of the rules of thumb. The structural model evaluation can be seen in Fig. 2 below.

\section{Experimental design, materials, and methods}

This data article used a quantitative research method approach. The data analysis unit were organisations. The research population consisted of all non-vocational private higher education institution in the area of Bandung, West Java, Indonesia taken from Ref. [10]. The number of samples of this research were the same as the total non-vocational private higher education institutions in the Bandung area, which were 81 . The sampling technique used was non-probability sampling, with saturated sampling making all of the members of the population the sample [11]. Each non-vocational private higher education institution had an average of 10 respondents, so the total number of respondents who would filled the questionnaire were 810 . The questionnaire data were collected between May 2019 and September 2019. The questionnaire data that were collected and found to be suitable for the analyzing were 530 questionnaires from 64 non-vocational private higher education institutions. The response rate of the data collection was $65.43 \%$. The data collected has fulfilled the minimum requirements of the Smart PLS sample size recommendation, with a range of 8-90 organisations for theoretical models with a significance level of 5\% [8]. The data collected were analyzed into SPSS for common method variance in order to evaluate whether the research indicators are free of bias [7]. Descriptive statistics were used to know the respondent's profile.

Table 9

$\mathrm{R}^{2}$ values.

\begin{tabular}{lllllc}
\hline & $\begin{array}{l}\text { Original } \\
\text { Sample (O) }\end{array}$ & Sample Mean $(\mathrm{M})$ & $\begin{array}{l}\text { Standard Deviation } \\
(\text { STDEV })\end{array}$ & $\begin{array}{l}\text { T Statistics } \\
(|\mathrm{O} / \mathrm{STDEV}|)\end{array}$ & $\begin{array}{l}\text { P Values } \\
\end{array}$ \\
\hline Innovation Ambidexterity & 0.680 & 0.681 & 0.030 & 22.929 & $\mathbf{0 . 0 0 0}$ \\
Sustainable Competitive Advantage & 0.523 & 0.526 & 0.044 & 12.018 & $\mathbf{0 . 0 0 0}$ \\
\hline
\end{tabular}

The definition of significance of bold is if the p-value less than 0.05 . 
Table 10

$\mathrm{Q}^{2}$ values.

\begin{tabular}{llll}
\hline & SSO & SSE & $\mathrm{Q}^{2}(=1-\mathrm{SSE} / \mathrm{SSO})$ \\
\hline Absorptive Capacity & $6,360.000$ & $6,360.000$ & \\
Innovation Ambidexterity & $3,180.000$ & $1,863.092$ & 0.414 \\
Sustainable Competitive Advantage & $4,770.000$ & $3,343.784$ & 0.299 \\
\hline
\end{tabular}

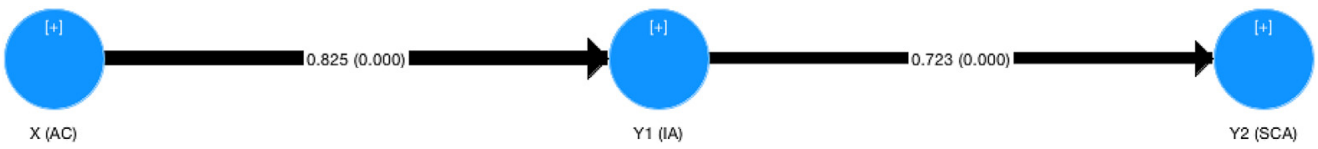

Fig. 2. Structural model evaluation.

Smart PLS was used with the considerations as follow [8]:

1. Aims to identify the key driver of a variable (measurement model)

2. Can be used to structure complex theoretical models (consisting of many indicators)

3. Can be used for small sample sizes and for data that is not normally distributed

4. Aim at analysing the latent variables (structural model)

SmartPLS was used for the measurement model evaluation and structural model evaluation [8]. The measurement model evaluation was first used in the analyzing of the Smart PLS data in order to examine the feasibility of the research indicators. All of the indicators are stated to have met the rule of thumb. The measurement model evaluation was followed by the structural model evaluation. The structural model evaluation was used to examine the nexus between the research variables with conclusions that were either significant or not. The data analyzing in the structural model evaluation used the complete bootstrapping 5000 sample method inclusive of the two-tailed BCa confidence interval method and a 0.05 confidence level.

\section{Acknowledgements}

1. LPDP (Indonesia Endowment Fund for Education) as a research funder.

2. LPPM Telkom University as a publication funder.

\section{Conflict of Interest}

The authors declare that they have no known competing financial interests or personal relationships that could have appeared to influence the work reported in this paper.

\section{Appendix A. Supplementary data}

Supplementary data to this article can be found online at https://doi.org/10.1016/j.dib.2020.105200.

\section{References}

[1] C. Camisón, B. Forés, Knowledge absorptive capacity: new insights for its conceptualization and measurement, J. Bus. Res. 63 (7) (2010) 707-715.

[2] J.L. Soares, D. Roberto, J. Carlos, P. José, S. Neto, "Organizational Ambidexterity: a study in Brazilian higher education institutions, J. Technol. Manag. Innovat. 13 (3) (2018) 36-46.

[3] A. Sengupta, A.S. Ray, University research and knowledge transfer: a dynamic view of ambidexterity in british universities, Res. Pol. 46 (5) (2017) 881-897.

[4] Kementerian Riset, Teknologi, “Klasterisasi Perguruan Tinggi Indonesia Tahun 2017.", 2017. Available, https://www. kopertis12.or.id/wp-content/uploads/2017/08/Pemeringkatan-PT-2017-min.pdf. (Accessed 1 February 2020). 
[5] O.R. Mahdi, I.A. Nassar, M.K. Almsafir, Knowledge management processes and sustainable competitive advantage: an empirical examination in private universities, J. Bus. Res. 94 (2019) 320-334, https://doi.org/10.1016/j.jbusres.2018.02.013. ISSN 0148-2963.

[6] A. Pangarso, Mendeley Data - Questionnaire Data of Innovation Ambidexterity, Absorptive Capacity and Sustainable Competitive Advantage, Mendeley Data, 2020 [Online]. Available, https:/data.mendeley.com/datasets/z2y8gmxtrb/3. (Accessed 10 January 2020).

[7] W.E. Saris, I.N. Gallhofer, Design, Evaluation, and Analysis of Questionnaires for Survey Research, 2014.

[8] J.F.J. Hair, G.T.M. Hult, C.M. Ringle, M. Sarstedt, A Primer on Partial Least Squares Structural Equation Modeling, PLS-SEM, 2017.

[9] S.P. Gudergan, et al., A new criterion for assessing discriminant validity in variance-based structural equation modeling, Australas. Mark. J. 57 (1) (2019), 0-5.

[10] PDDIKTI, SRV2 PDDIKTI: Pangkalan Data Pendidikan Tinggi, 2018 [Online]. Available, https://forlap.ristekdikti.go.id/ perguruantinggi/search. (Accessed 23 August 2018).

[11] M. Newhart, M.L. Patten, Understanding Research Methods: an Overview of the Essentials, Taylor \& Francis, 2018. 